\title{
ESTIMATION OF THE TIME SINCE DEATH BY USING THE POLARIZATION MULLER-MATRIX MICROSCOPY OF BIOLOGICAL TISSUE IN CASES OF ALCOHOL AND CARBON MONOXIDE POISONING

\author{
Ihor Ivaskevich $^{1}$, Oleh Vanchuliak ${ }^{2}$, Viktor Bachynskiy ${ }^{3}$, Sviatoslava Yurniuk ${ }^{4}$
}

\begin{abstract}
:
Introduction: This paper aims to investigate and substantiate the information capabilities of the objective method of azimuthal-invariant polarization Müller-matrix microscopy of histological sections of biological tissues (BT) in the diagnosis of time since death (TSD) in alcohol and monoxide poisoning.

Objectives: The purpose of the study was to evaluate the diagnostic capabilities of the azimuthal-invariant Muller-matrix polarimetry technique of the polycrystalline constituent of BT and human body fluids in determining the TSD in cases of alcohol and carbon monoxide poisoning.

Results: A comprehensive experimental study of the diagnostic efficiency of the azimuthal-invariant Muller-matrix polarimetric microscopy of the polycrystalline component of histological sections of the brain, myocardium, adrenal glands, liver, and polycrystalline blood films from dead persons for the diagnosis of TSD in cases of alcohol and carbon monoxide poisoning.A sensitivity range of 24 hours was determined using the method of the azimuthal-invariant Muller-matrix polarimetric microscopy of the polycrystalline component of histological sections of the myocardium for the diagnosis of TSD in cases of alcohol and carbon monoxide poisoning.

Conclusion: The results showed the effectiveness of the studied methodology and the prospect of further research in this direction.
\end{abstract}

UDC Classification: 616-091, DOI: https://doi.org/10.12955/pmp.v1.96

Keywords: Post-mortem interval, carbon monoxide poisoning, alcohol poisoning, polarization.

\section{Introduction}

Determining the TSD of a person continues to be one of the most important issues to be resolved during the forensic examination of a dead body. In the early post-mortem period, a wide variety of methods (subjective and objective) exist for solving this issue (Gonnade \& Chavan, 2018; Shaaban ElRaouf et al., 2017; Tomé, 2017). However, there is currently no single method of assessment that can ensure the accuracy and reproducibility of the result. At the same time, attention is drawn to the lack of information on specific morphological changes in BT in various pathological conditions, such as, poisoning with alcohol and carbon monoxide (Hayden, 2019; Kim et al, 2018; Rose et al, 2017). Therefore, it is now necessary to develop and implement new methods for determining the time since death.

A new step was the application and development of laser polarimetric methods of microscopic examination of optically inhomogeneous biological structures using statistical analysis of digital polarization maps. The study of Ushenko (2015) confirmed that these methods provide almost complete information about the polycrystalline structure of BT and fluids of the human body and allow to examine the dynamics of changes in different pathological conditions for the diagnosis of the post-mortem interval.

\section{Purpose}

The purpose of the study was to evaluate the diagnostic capabilities of the azimuthal-invariant Mullermatrix polarimetric microscopy of the polycrystalline constituent of BT and human body fluids in determining the TSD in cases of alcohol and carbon monoxide poisoning.

\footnotetext{
${ }^{1}$ Higher State Educational Establishment of Ukraine "Bukovinian State Medical University", Forensic Medicine and Medical Law Department, Chernivtsi, Ukraine, liquiritia.s@gmail.com

${ }^{2}$ Higher State Educational Establishment of Ukraine "Bukovinian State Medical University", Forensic Medicine and Medical Law Department, Chernivtsi, Ukraine

${ }^{3}$ Higher State Educational Establishment of Ukraine "Bukovinian State Medical University", Forensic Medicine and Medical Law Department, Chernivtsi, Ukraine

${ }^{4}$ Higher State Educational Establishment of Ukraine "Bukovinian State Medical University", Pharmacy

Department, Chernivtsi, Ukraine
} 


\section{Materials and Methods}

The object of the study was histological sections of the brain, liver, adrenal glands, myocardium and polycrystalline blood films, selected from 56 corpses of both sexes, aged 18 to 71 years, with a preknown time of onset of death, ranging from 1 to 40 hours. All samples were divided into two experimental groups by cause of death: (i) due to ethanol poisoning (ii) due to carbon monoxide poisoning. BT samples from the persons deceased due to coronary heart disease were used as control group with a sample size of 17 . The basic principle of our modeling process was based on the use of microscopic images of biological layers of human tissue and fluid, which were well-established Müller-matrix polarimetric analytical approach for the diagnosis of morphological and molecular work of BT. (Ushenko et al, 2016). According to this approach, the biological object is considered as a twocomponent ("isotropic-anisotropic") structural matrix.

The basis of developing objective digital criteria for forensic diagnostics of TSD in cases of alcohol and carbon monoxide poisoning is based on the azimuthal-invariant Muller-matrix polarimetry of the polycrystalline constituent of BT and fluids of the human body. The research methodology is illustrated by the following scheme (Figure 1).

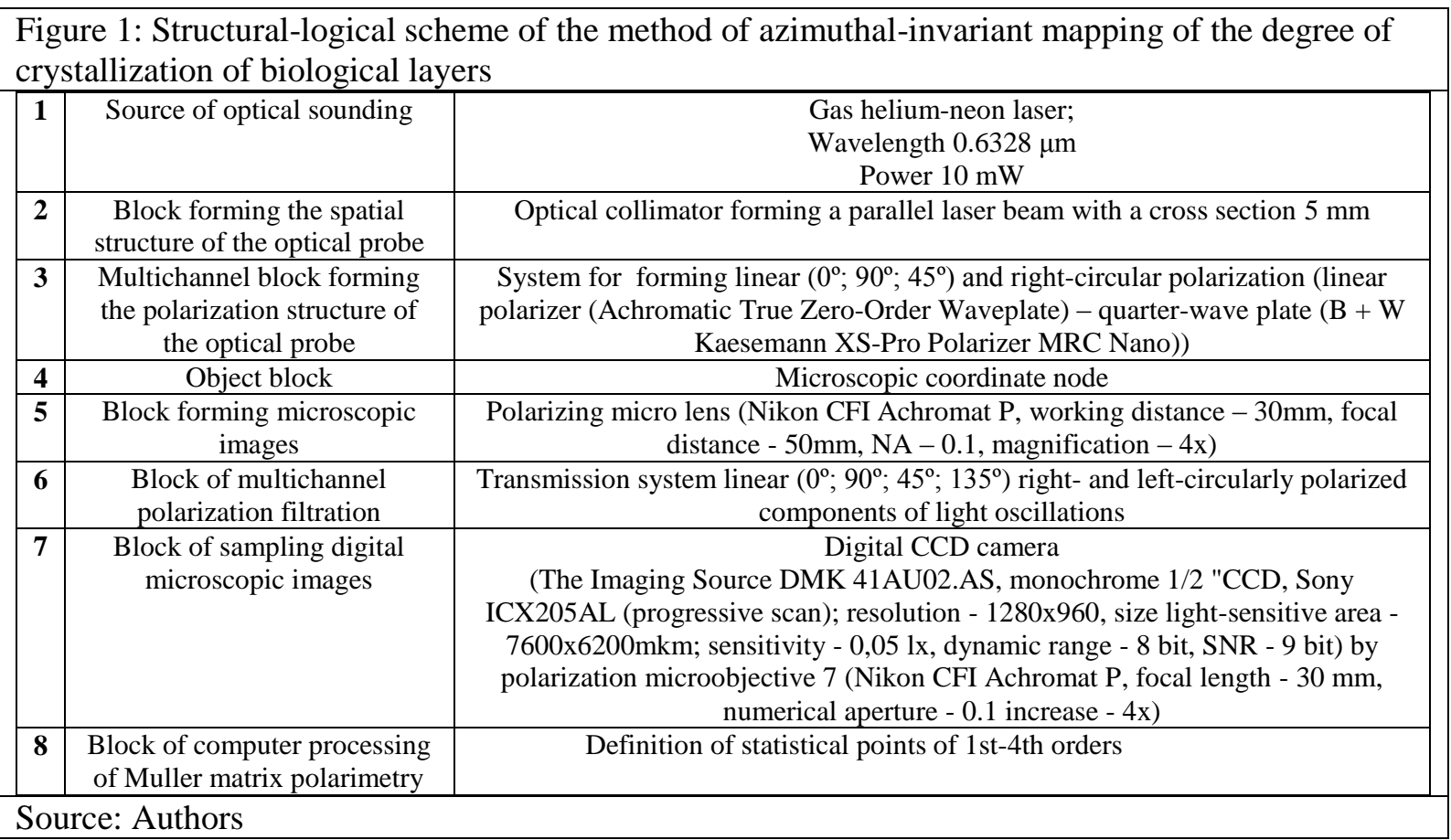

The experimental methodology of azimuth-invariant Muller-matrix polarization microscopy includes the following steps:

- For each of the representative samples of BT, Muller-matrix invariant (MMI) maps of polycrystalline component of histological sections of internal organs and blood films were experimentally determined;

- Values of the statistical moments in the range of 1st to 4th orders ( $S r, D p, A s, E k$ ), which characterize the MMI size distributions for each individual sample of BT, were calculated;

- Average value and the error of the magnitude of each of the central statistical moments in range of 1 st to 4 th orders were determined within the control and two experimental groups of BT;

- For each of the central statistical moments in range of 1 st to 4 th orders, which characterize MMI distributions, statistical reliability of differentiation of MMI maps of the polycrystalline component of histological sections of BT of internal organs and blood films was established;

- within the principles of evidence-based medicine, the operational characteristics of the force of the azimuthal-invariant Muller-matrix polarization microscopy method were calculated: sensitivity, specificity, balanced accuracy. 
Thus, the temporal changes in the statistical moments of MMI distribution of BT preparations of the human body were determined: brain, liver, adrenal glands, myocardium, and polycrystalline blood films for both experimental and control groups.

\section{Histological sections of the brain}

Table 1 summarizes the results of monitoring of temporal changes in the statistical structure of the Muller-matrix images of the polycrystalline component of histological sections of the brain of all three groups of deaths with different TSD.

\begin{tabular}{|c|c|c|c|c|c|}
\hline T, hours & 6 & 8 & 10 & 16 & $>24$ \\
\hline Options & \multicolumn{5}{|c|}{ Control Group (CHD) } \\
\hline$S M_{3}$ & $0.36 \pm 0.014$ & $0.54 \pm 0.21$ & $0.77 \pm 0.34$ & $1.41 \pm 0.64$ & $1.36 \pm 0.61$ \\
\hline$P$ & \multicolumn{4}{|c|}{$p<0.05$} & $p<0.05$ \\
\hline $\mathrm{SM}_{4}$ & $1.36 \pm 0.061$ & $2.14 \pm 0.195$ & $2.92 \pm 0.13$ & $5.31 \pm 0.22$ & $5.22 \pm 0.21$ \\
\hline$P$ & \multicolumn{4}{|c|}{$p<0.05$} & $p<0.05$ \\
\hline $\mathrm{T}$, hours & 6 & 8 & 10 & 16 & $>24$ \\
\hline Options & \multicolumn{5}{|c|}{ Study group 1 (alcohol poisoning) } \\
\hline$S M_{3}$ & $0.71 \pm 0.034$ & $1.06 \pm 0.044$ & $1.51 \pm 0.071$ & $2.62 \pm 0.11$ & $2.57 \pm 0.11$ \\
\hline$P$ & \multicolumn{4}{|c|}{$p<0.05$} & $p<0.05$ \\
\hline$S M_{4}$ & $1.07 \pm 0.052$ & $1.68 \pm 0.73$ & $2.27 \pm 0.105$ & $4.08 \pm 0.18$ & $3.99 \pm 0.17$ \\
\hline$P$ & \multicolumn{4}{|c|}{$p<0.05$} & $p<0.05$ \\
\hline T, hours & 6 & 8 & 10 & 16 & $>24$ \\
\hline Options & \multicolumn{5}{|c|}{ Study group 2 (carbon monoxide poisoning) } \\
\hline$S M_{3}$ & $1.23 \pm 0.059$ & $1.88 \pm 0.087$ & $2.57 \pm 0.11$ & $4.33 \pm 0.19$ & $4.28 \pm 0.19$ \\
\hline$P$ & \multicolumn{4}{|c|}{$p<0.05$} & $p<0.05$ \\
\hline $\mathrm{SM}_{4}$ & $0.86 \pm 0.042$ & $1.44 \pm 0.065$ & $2.07 \pm 0.094$ & $3.99 \pm 0.17$ & $3.87 \pm 0.17$ \\
\hline$P$ & \multicolumn{4}{|c|}{$p<0.05$} & $p<0.05$ \\
\hline
\end{tabular}

Source: Authors

Table 2: Temporal dynamics of change of statistical moments of the 3rd - 4th orders, characterizing distributions of size of MMI of polycrystalline blood films (T, hours).

\begin{tabular}{|c|c|c|c|c|c|}
\hline T, hours & 6 & 8 & 10 & 18 & $>24$ \\
\hline Options & \multicolumn{5}{|c|}{ Control Group (CHD) } \\
\hline$S M_{3}$ & $0.11 \pm 0.004$ & $0.16 \pm 0.007$ & $0.21 \pm 0.009$ & $0.38 \pm 0.016$ & $0.36 \pm 0.015$ \\
\hline$P$ & \multicolumn{4}{|c|}{$p<0.05$} & $p<0.05$ \\
\hline$S M_{4}$ & $0.095 \pm 0.0049$ & $0.15 \pm 0.006$ & $0,21 \pm 0,009$ & $0,44 \pm 0,018$ & $0.42 \pm 0.017$ \\
\hline$P$ & \multicolumn{4}{|c|}{$p<0.05$} & $p<0.05$ \\
\hline T, hours & 6 & 8 & 10 & 18 & $>24$ \\
\hline Options & \multicolumn{5}{|c|}{ Study group 1 (alcohol poisoning) } \\
\hline$S M_{3}$ & $0.21 \pm 0.009$ & $0.29 \pm 0.012$ & $0.38 \pm 0.016$ & $0.71 \pm 0.031$ & $0.68 \pm 0.029$ \\
\hline$P$ & \multicolumn{4}{|c|}{$p<0.05$} & $p<0.05$ \\
\hline$S M_{4}$ & $0.19 \pm 0.011$ & $0.31 \pm 0.014$ & $0.43 \pm 0.018$ & $0.91 \pm 0.042$ & $0.88 \pm 0.039$ \\
\hline$P$ & \multicolumn{4}{|c|}{$p<0.05$} & $p<0.05$ \\
\hline T, hours & 6 & 8 & 10 & 18 & $>24$ \\
\hline Options & \multicolumn{5}{|c|}{ Study group 2 (carbon monoxide poisoning) } \\
\hline$S M_{3}$ & $0.61 \pm 0.031$ & $0.92 \pm 0.041$ & $1.24 \pm 0.052$ & $2.14 \pm 0.099$ & $2.08 \pm 0.098$ \\
\hline$P$ & \multicolumn{4}{|c|}{$p<0.05$} & $p<0.05$ \\
\hline$S M_{4}$ & $1.11 \pm 0.094$ & $1.74 \pm 0.078$ & $2.39 \pm 0.105$ & $4.21 \pm 0.19$ & $4.18 \pm 0.19$ \\
\hline$P$ & \multicolumn{4}{|c|}{$p<0.05$} & $p<0.05$ \\
\hline
\end{tabular}

\section{Source: Authors}

The obtained results show that the linear range of change in the magnitude of the central statistical moments is in the range of 14 order, which characterize the asymmetry and excess of the MMI size distribution of histological sections of the brain of the deceased, with the largest TSD being 18 hours. 
- Value of the statistical moment of the $3^{\text {rd }}$ order (asymmetry) varies within the following range:

- Group 1: 0.36 to 1.41 ;

- Group 2: 0.71 to 2.62 ;

- Group 3: 1.23 to 4.33 ;

- Value of the statistical moment of the 4th order (excess) varies within the following range:

- Group 1: 1.36 to 5.31;

- Group 2: 1.07 to 4.08

- Group 3: 0.86 to 3.99 .

\section{Polycrystalline blood films}

Table 2 summarizes the results of monitoring of temporal dynamics of necrotic changes in the statistical structure of the Muller map-matrix images of the optically anisotropic component of polycrystalline blood films of all three groups of deaths with different TSD.

The obtained results highlight that the linear range of change in the magnitude of the central statistical moments is between 1 to 4 order, which characterize the asymmetry and excess of the MMI size distribution of the polycrystalline blood films of the deceased, with the largest TSD being 18 hours:

- Value of the statistical moment of the 3rd order (asymmetry) varies within the following range:

- Group 1: 0.11 to 0.38 ;

- Group 2: 0.21 to 0.71 ;

- Group 3: 0.61 to 2.14;

- Value of the statistical moment of the 4th order (excess) varies within the following range:

- Group 1: 0.095 to 0.44

- Group 2: 0.19 to 0.91 ;

- Group 3: 1.11 to 4.21 .

\section{Histological sections of the liver}

Table 3 summarizes the results of the monitoring of temporal dynamics of necrotic change in the coordinate structure of the Muller-matrix images of the polycrystalline component of the histological sections of the liver of all three groups of deaths with different TSD.

\begin{tabular}{|c|c|c|c|c|c|}
\hline $\mathrm{T}$, hours & 6 & 8 & 14 & 20 & $>24$ \\
\hline Options & \multicolumn{5}{|c|}{ Control Group (CHD) } \\
\hline$S M_{3}$ & $0.71 \pm 0.034$ & $0.89 \pm 0.041$ & $1.38 \pm 0.059$ & $1.98 \pm 0.088$ & $1.91 \pm 0.088$ \\
\hline$P$ & \multicolumn{4}{|c|}{$p<0.05$} & $p<0.05$ \\
\hline$S M_{4}$ & $0.54 \pm 0.025$ & $0.72 \pm 0.031$ & $1.28 \pm 0.055$ & $1.67 \pm 0.073$ & $1.61 \pm 0.071$ \\
\hline$P$ & \multicolumn{4}{|c|}{$p<0.05$} & $p<0.05$ \\
\hline T, hours & 6 & 8 & 14 & 20 & $>24$ \\
\hline Options & \multicolumn{5}{|c|}{ Study group 1 (alcohol poisoning) } \\
\hline$S M_{3}$ & $1.21 \pm 0.062$ & $1.49 \pm 0.069$ & $2.32 \pm 0.105$ & $3.88 \pm 0.17$ & $3.79 \pm 0.16$ \\
\hline$P$ & \multicolumn{4}{|c|}{$p<0.05$} & $p<0.05$ \\
\hline$S M_{4}$ & $0.89 \pm 0.043$ & $1.11 \pm 0.049$ & $1.79 \pm 0.076$ & $2.81 \pm 0.12$ & $2.77 \pm 0.12$ \\
\hline$P$ & \multicolumn{4}{|c|}{$p<0.05$} & $p<0.05$ \\
\hline T, hours & 6 & 8 & 14 & 20 & $>24$ \\
\hline Options & \multicolumn{5}{|c|}{ Study group 2 (carbon monoxide poisoning) } \\
\hline $\mathrm{SM}_{3}$ & $1.85 \pm 0.081$ & $2.24 \pm 0.099$ & $3.47 \pm 0.15$ & $4.66 \pm 0.21$ & $4.58 \pm 0.22$ \\
\hline$P$ & \multicolumn{4}{|c|}{$p<0.05$} & $p<0.05$ \\
\hline$S M_{4}$ & $1.43 \pm 0.067$ & $1.81 \pm 0.088$ & $3.03 \pm 0.13$ & $4.12 \pm 0.18$ & $4.07 \pm 0.17$ \\
\hline$P$ & \multicolumn{4}{|c|}{$p<0.05$} & $p<0.05$ \\
\hline
\end{tabular}

Source: Authors

Here, the linear range of change in the magnitude of the central statistical moments is between 1st 4th orders, which characterize the asymmetry and excess of the MMI size distribution of the histological sections of the liver of the deceased, with the largest TSD being 20 hours; 
- Value of the statistical moment of the 3rd order (asymmetry) varies within the following range:

- Group 1: 0.71 to 1.98 ;

- Group 2: 1.21 to 3.88

- Group 3: 1.85 to 4.66;

- Value of the statistical moment of the 4th order (excess) varies within the following range:

- Group 1: 0.54 to 1.67 ;

- Group 2: 0.89 to 2.81 ;

- Group 3: 1.43 to 4.12 .

\section{Histological sections of the adrenal glands}

Table 4 illustrates the results of monitoring of temporal dynamics of necrotic change in the coordinate structure of the Muller-matrix images of the polycrystalline component of histological sections of the adrenal glands of all three groups of dead with different TSD.

\begin{tabular}{|c|c|c|c|c|c|}
\hline T, hours & 6 & 8 & 14 & 20 & $>24$ \\
\hline Options & \multicolumn{5}{|c|}{ Control Group (CHD) } \\
\hline$S M_{3}$ & $0.31 \pm 0.014$ & $0.36 \pm 0.014$ & $0.49 \pm 0.022$ & $0.64 \pm 0.027$ & $0.61 \pm 0.026$ \\
\hline$P$ & \multicolumn{4}{|c|}{$p<0.05$} & $p<0.05$ \\
\hline$S M_{4}$ & $0.26 \pm 0.013$ & $0.37 \pm 0.016$ & $0.59 \pm 0.021$ & $0.82 \pm 0.035$ & $0.79 \pm 0.033$ \\
\hline$P$ & \multicolumn{4}{|c|}{$p<0.05$} & $p<0.05$ \\
\hline T, hours & 6 & 8 & 14 & 20 & $>24$ \\
\hline Options & \multicolumn{5}{|c|}{ Study group 1 (alcohol poisoning) } \\
\hline$S M_{3}$ & $0.62 \pm 0.031$ & $0.74 \pm 0.032$ & $1.07 \pm 0.044$ & $1.42 \pm 0.068$ & $1.39 \pm 0.069$ \\
\hline$P$ & \multicolumn{4}{|c|}{$p<0.05$} & $p<0.05$ \\
\hline$S M_{4}$ & $0.81 \pm 0.042$ & $1.03 \pm 0.043$ & $1.72 \pm 0.078$ & $2.39 \pm 0.11$ & $2.26 \pm 0.105$ \\
\hline$P$ & \multicolumn{4}{|c|}{$p<0.05$} & $p<0.05$ \\
\hline T, hours & 6 & 8 & 14 & 20 & $>24$ \\
\hline Options & \multicolumn{5}{|c|}{ Study group 2 (carbon monoxide poisoning) } \\
\hline$S M_{3}$ & $0.51 \pm 0.024$ & $0.63 \pm 0.027$ & $0.99 \pm 0.042$ & $1.49 \pm 0.067$ & $1.44 \pm 0.065$ \\
\hline$P$ & \multicolumn{4}{|c|}{$p<0.05$} & $p<0.05$ \\
\hline$S M_{4}$ & $0.74 \pm 0.031$ & $0.98 \pm 0.043$ & $1.73 \pm 0.077$ & $2.49 \pm 0.11$ & $2.38 \pm 0.11$ \\
\hline$P$ & \multicolumn{4}{|c|}{$p<0.05$} & $p<0.05$ \\
\hline
\end{tabular}

\section{Source: Authors}

The linear range of change in the magnitude of the central statistical moments of 1 st- 4th orders, which characterize the asymmetry and excess of the MMI size distribution of histological sections of the adrenal glands of the deceased, with the largest TSD being 20 hours.

- Value of the statistical moment of the 3rd order (asymmetry) varies within the following range:

- $\quad$ Group 1: 0.31 to 0.64 ;

- $\quad$ Group 2: 0.62 to 1.42 ;

- $\quad$ Group 3: 0.51 to 1.49 ;

- Value of the statistical moment of the 4th order (excess) varies within the following range:

- $\quad$ Group 1: 0.26 to 0.82 ;

- $\quad$ Group 2: 0.81 to 2.39;

- $\quad$ Group 3: 0.74 to 2.49 .

\section{Histological sections of the myocardium}

Table 5 illustrates the results of the monitoring of temporal dynamics of necrotic change in the coordinate structure of the Muller-matrix images of polycrystalline component of histological sections of the myocardium of all three groups of dead with different TSD.

The results show that the linear range of change in the magnitude of the central statistical moments is between 1st to 4th orders, which characterize the asymmetry and excess of the MMI size distribution of histological sections of the myocardium of the deceased, with the largest TSD is 24 hours. 


\begin{tabular}{|c|c|c|c|c|c|}
\hline $\mathrm{T}$, hours & 6 & 8 & 12 & 24 & $>36$ \\
\hline Options & \multicolumn{5}{|c|}{ Control Group (CHD) } \\
\hline $\mathrm{SM}_{3}$ & $0.93 \pm 0.046$ & $1.01 \pm 0.043$ & $1.15 \pm 0.049$ & $1.56 \pm 0.063$ & $1.51 \pm 0.062$ \\
\hline$P$ & \multicolumn{4}{|c|}{$p<0.05$} & $p<0.05$ \\
\hline $\mathrm{SM}_{4}$ & $0.66 \pm 0.031$ & $0.74 \pm 0.031$ & $0.85 \pm 0.039$ & $1.28 \pm 0.055$ & $1.21 \pm 0.054$ \\
\hline$P$ & \multicolumn{4}{|c|}{$p<0.05$} & $p<0.05$ \\
\hline T, hours & 6 & 8 & 12 & 24 & $>36$ \\
\hline Options & \multicolumn{5}{|c|}{ Study group 2 (carbon monoxide poisoning) } \\
\hline$S M_{3}$ & $1.38 \pm 0.065$ & $1.51 \pm 0.068$ & $1.77 \pm 0.072$ & $2.23 \pm 0.098$ & $2.18 \pm 0.096$ \\
\hline$P$ & \multicolumn{4}{|c|}{$p<0.05$} & $p<0.05$ \\
\hline$S M_{4}$ & $0.95 \pm 0.045$ & $1.03 \pm 0.041$ & $1.24 \pm 0.053$ & $2.06 \pm 0.094$ & $2.01 \pm 0.091$ \\
\hline$P$ & \multicolumn{4}{|c|}{$p<0.05$} & $p<0.05$ \\
\hline $\mathrm{T}$, hours & 6 & 8 & 12 & 24 & $>36$ \\
\hline Options & \multicolumn{5}{|c|}{ Study group 2 (carbon monoxide poisoning) } \\
\hline $\mathrm{SM}_{3}$ & $2.03 \pm 0.11$ & $2.27 \pm 0.105$ & $2.68 \pm 0.11$ & $3.51 \pm 0.15$ & $3.47 \pm 0.15$ \\
\hline$P$ & \multicolumn{4}{|c|}{$p<0.05$} & $p<0.05$ \\
\hline $\mathrm{SM}_{4}$ & $1.81 \pm 0.092$ & $2.01 \pm 0.097$ & $2.44 \pm 0.11$ & $3.33 \pm 0.14$ & $3.24 \pm 0.14$ \\
\hline$P$ & \multicolumn{4}{|c|}{$p<0.05$} & $p<0.05$ \\
\hline
\end{tabular}

- Value of the central statistical moment of 3rd order (asymmetry) varies within the following range:

- Group 1: 0.93 to 1.56 ;

- Group 2: 1.38 to 2.23;

- $\quad$ Group 3: 2.03 to 3.51;

- Value of the central statistical moment of the 4th order (excess) varies within the following range:

- Group 1: 0.66 to 1.28;

- Group 2: 0.95 to 2.06;

- Group 3: 1.81 to 3.33.

Accordingly, by azimuth-invariant Muller-matrix mapping of microscopic images of BT and body fluids, time intervals of determination of TSD for control and experimental groups were obtained. (Table 6)

\begin{tabular}{|c|c|}
\hline \multicolumn{2}{|c|}{ Table 6: TSD time intervals } \\
\hline \multicolumn{2}{|c|}{ Muller-matrix mapping } \\
\hline Histological section of the brain & 16 hours \\
\hline Polycrystalline film of blood & 18 hours \\
\hline Histological section of the liver & 20 hours \\
\hline Histological section of the adrenal glands & 20 hours \\
\hline Histological section of the myocardium & 24 hours \\
\hline Source: Authors
\end{tabular}

The results obtained confirmed the linear dependence of morphological changes in BT and human blood samples from the time of death, and their differential features depending on the cause of death.

\section{Conclusion}

A comprehensive experimental study of the diagnostic efficiency of the azimuthal-invariant Mullermatrix polarimetric microscopy of the polycrystalline component of histological sections of the brain, myocardium, adrenal glands, liver and polycrystalline blood films of dead persons for the diagnosis of TSD in cases of alcohol and carbon monoxide poisoning. A sensitivity range of 24 hours was determined from the method of the azimuthal-invariant Muller-matrix polarimetric microscopy of the polycrystalline component of histological sections of the myocardium for the diagnosis of TSD in cases of alcohol and carbon monoxide poisoning. The results revealed the effectiveness of the studied methodology and the prospect of further research in this direction. 


\section{References}

Gonnade, U., \& Chavan, K. D. (2018). Study of early postmortem changes in skin for estimation of postmortem interval at pims, loni. Journal of Indian Academy of Forensic Medicine, 40(4), 396-400, doi: https://doi.org/10.5958/09740848.2018.00088.X

Hayden, J. (2019). Ethanol determination using automated analyzers: limitations and pitfalls. In A. Dasgupta, \& J. Sepulveda, (eds.), Accurate Results in the Clinical Laboratory: A Guide to Error Detection and Correction (pp. 271-291). Elsevier.

Kim, H. H., Choi, S. C., Chae, M. K., \& Min, Y. G. (2018). Neuroprotective effect of ethanol in acute carbon monoxide intoxication: A retrospective study. Medicine (Baltimore),97(1), doi: https://doi.org/10.1097/MD.0000000000009569

Rose, J. J., Wang, L., Xu, Q., McTiernan, C. F., Shiva, S., Tejero, J., \& Gladwin, M. T. (2017). Carbon monoxide poisoning: pathogenesis, management, and future directions of therapy. American Journal of Respiratory and Critical Care Medicine, 195(5), 596-606, doi: https://doi.org/10.1164/rccm.201606-1275CI

Shaaban El-Raouf, A. A., Farrag, I. M., \& Bayoumy, E. S. (2017). Estimation of early postmortem interval by biochemical changes in brain and liver of rats using some oxidant and antioxidant parameters. The Egyptian Journal of Forensic Sciences and Applied Toxicology, 17(1), 147-162, doi: https://doi.org/10.21608/EJFSAT.2017.46108

Tomé, M. C. F. (2017). Estimation of Postmortem Interval Based on Cell Death Progression in Biological Fluids (Masters dissertationthe Faculty of Medicine, University of Porto,Porto, Portugal.

Ushenko, A.G., Dubolazov, A.V., Ushenko, V.A., Ushenko, Yu.A., Pidkamin, L.Y., Soltys, I.V. ... Pavlyukovich, N. (2016). Mueller-matrix mapping of optically anisotropic fluorophores of molecular biological tissues in the diagnosis of death causes. Proceedings of SPIE, 9971, Applications of Digital Image Processing, XXXIX, 99712L, doi: https://doi.org/10.1117/12.2237662

Ushenko, V. A., Prysyazhnyuk, V. P., Dubolazov, O. V., Karachevtsev, A. O., Olar, O. I., Olar, O. V., ... Savich, V. O. (2015). Polarization-correlation microscopy of human liquid polycrystalline films in infertility diagnosis. Proceedings of SPIE, 9599, Applications of Digital Image Processing, XXXVIII, 959922,doi: https://doi.org/10.1117/12.2187448 